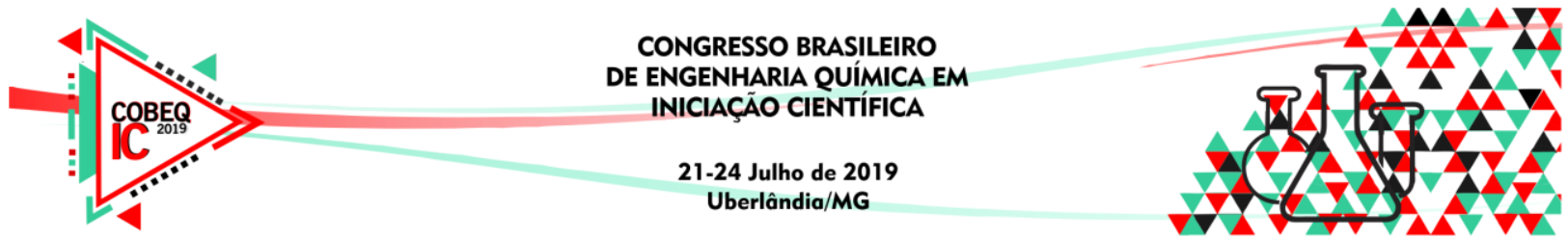

\title{
ANÁLISE COMPARATIVA DO ENSAIO MECÂNICO DE TRAÇÃO EM COMPÓSITO POLIMÉRICO COM CARGA INDUSTRIAL DE CAULIM E LAMA VERMELHA
}

\author{
D. C. P. CRUZ ${ }^{1}$, J. E. A. SANTOS ${ }^{1}$, I.F.G. CASTRO ${ }^{1}$, A. J. G. SANTOS ${ }^{2}$ e J. A. S. \\ SOUZA $^{1}$ \\ ${ }^{1}$ Universidade Federal do Pará, Faculdade de Engenharia Química \\ ${ }^{2}$ Universidade Federal do Pará, Campus Ananindeua, Faculdade de Engenharia Química \\ E-mail para contato: delispalhetac@gmail.com
}

\begin{abstract}
RESUMO - Um novo destino para resíduos possibilita a geração de materiais com propriedades interessantes para engenharia de materiais. Neste trabalho desenvolveu-se materiais compósitos com porcentagem de carga mineral de caulim e lama vermelha com matriz polimérica composta de resina poliéster com acelerador de cobalto e catalisador. Os rejeitos foram preparados e caracterizados por difração de raio-X. A produção das placas foi realizada em moldes e prensada posteriormente de acordo com norma ASTM D 3039, com 10 corpos de provas para cada série. Para análises mecânicas realizou-se o ensaio de tração no qual o resíduo de caulim a $30 \%$ resultou em $31,44 \mathrm{MPa}$ e para lama vermelha a $20 \%$ correspondente a 32,32 MPa. A microscopia eletrônica de varredura mostra a superfície dos compósitos após os ensaios de tração na qual observou-se boa aderência do caulim com a matriz e para lama vermelha a formação de agregados de partículas.
\end{abstract}

\section{INTRODUÇÃO}

A principal característica do compósito é combinação de propriedades incomuns, isto ocorre por se tratar de um material multifásico composto por matriz e fase dispersa. Segundo Callister (2008) essa condição é gerada através do princípio de ação combinada, ou seja, a escolha da matéria-prima de forma criteriosa atentando-se para versatilidade, como polímeros, cerâmica, fibras, metais entre outros.

A viabilidade de redução dos rejeitos estimula o uso desses resíduos, como cargas minerais atuando como a fase dispersa, também chamada de reforço. Conforme Sakahara (2012) a mistura de polímeros com minerais tem efeito nas propriedades de produto final, seja na redução de custo, transformações na resistência elétrica, susceptibilidade magnética e propriedades mecânicas. Vale ressaltar que a composição química e a pureza da carga influência direta e indiretamente no desempenho e aplicação do compósito. (Albano et al., 2000)

Desse modo o presente trabalho tem o objetivo de analisar os compósitos de matriz polimérica com carga mineral de caulim e lama vermelha, assim como os resultados dos ensaios de tração e microscopia eletrônica de varredura comparando ambas. 


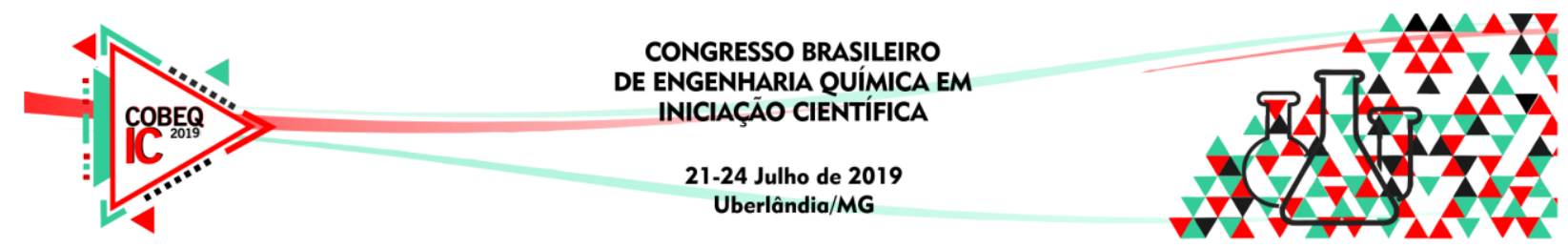

\section{METODOLOGIA}

\subsection{Preparação e caracterização dos rejeitos industriais}

Os resíduos de caulim e bauxita (lama vermelha) foram fornecidos pela empresa Imerys e Hydro Alunorte, respectivamente. Os resíduos foram submetidos a secagem em estufa durante 24 horas, à temperatura de $105^{\circ} \mathrm{C}$. Posteriormente realizou-se o peneiramento manual em peneira granulométrica 100 mesh da série Tyler. A identificação dos minerais presentes nas amostras foi obtida através da técnica de difração de raio-X (DRX), utilizando o equipamento difratômetro de Raios - X: D8 Advance da Bruker. A aquisição dos dados foi realizada com software X Pert Data collector, versão 3.0.

\subsection{Produção dos compósitos}

A resina utilizada no trabalho foi a Resina Poliéster isoftálico (Resina AM 910), de média reatividade, amarelada, não acelerada, com baixa viscosidade, boa resistência química e térmica ao redor de 95 a $110^{\circ} \mathrm{C}$. Como acelerador de cura, o de Cobalto, produto comercial denominado CAT MET UMEDECIDO (Solução de Octoato de cobalto $1,5 \% \mathrm{v} / \mathrm{v}$ ). O catalisador, produto comercial BUTANOX M-50. Todos provenientes da Aerojet ${ }^{\circledR}$ Brasileira de Fiberglass LTDA.

Pesou-se as massas da resina e do rejeito necessários para cada placa de acordo com sua porcentagem. A mistura foi colocada no molde e em seguida prensada, em prensa hidráulica com carga de $2,5 \mathrm{kN}$ durante o tempo estimado de 20 minutos. Foram produzidos 10 corpos de prova para cada carga mineral $(10 \%, 20 \%, 30 \%$ e $40 \%)$. Após a produção das placas, foram realizados os cortes nas placas de acordo com a norma ASTM D3039, conforme na figura 1 .

Figura 1 - Fluxograma de produção dos compósitos.

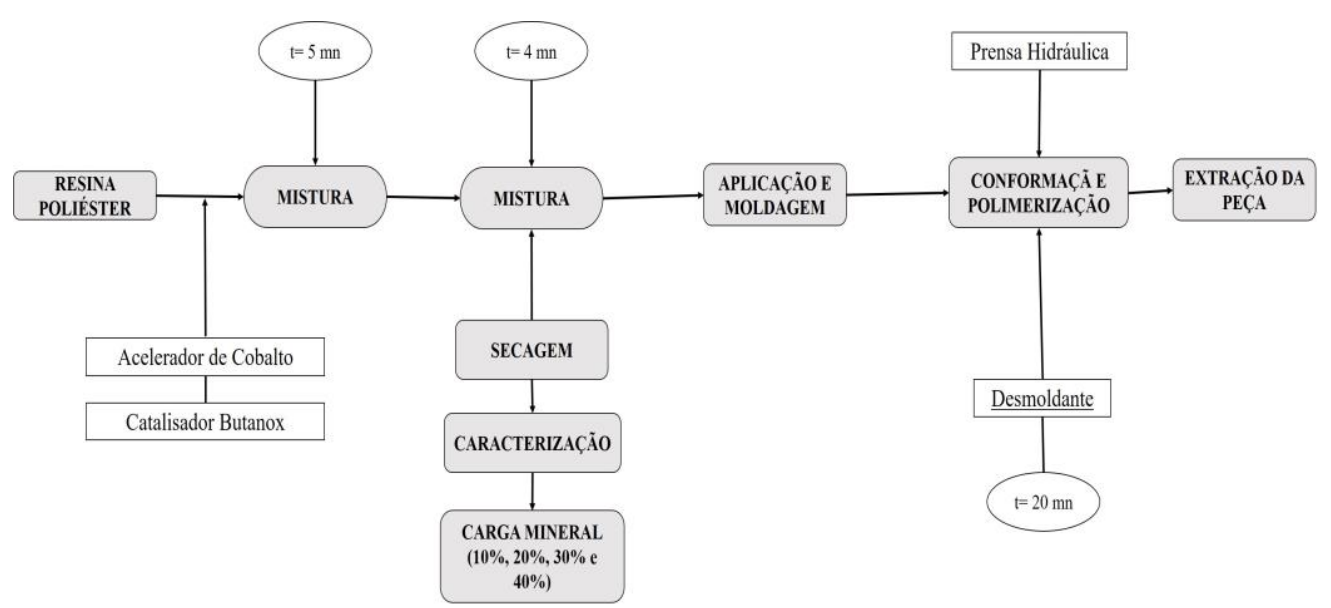

\subsection{Propriedade mecânica e microscopia eletrônica de varredura}

Os ensaios de tração dos corpos de prova foram realizados seguindo a norma ASTM D-3039. Utilizou-se a máquina universal de tração (KRATOS 1-modelo IKCL3) com sistema 


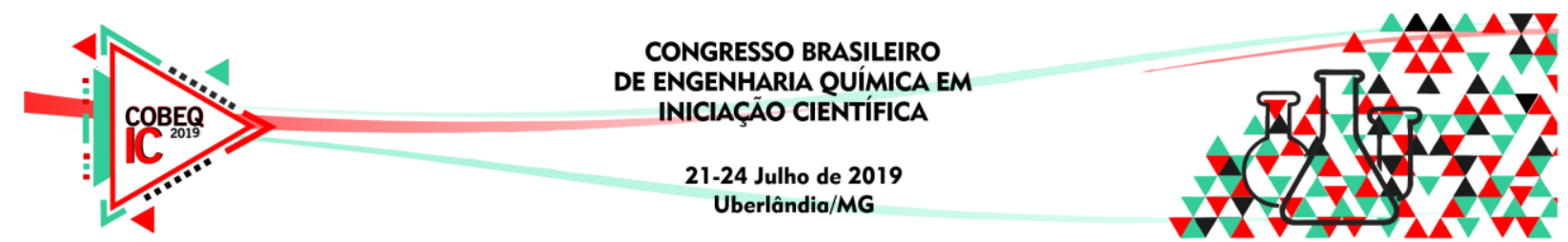

de aquisição de dados, com célula de carga de $5 \mathrm{kN}$, adotando velocidade de $2 \mathrm{~mm} / \mathrm{min}$ e comprimento útil para medição entre garras de $180 \mathrm{~mm}$, com dimensões (espessura x largura x comprimento) $(2,5 \mathrm{~mm}$ x $25 \mathrm{~mm}$ x $250 \mathrm{~mm})$.

Após a realização do ensaio mecânico, as superfícies de fratura dos corpos de prova foram analisadas de forma a observar as alterações morfológicas dos compósitos, por meio de microscópio eletrônico de varredura (MEV) X- Max, sendo que as amostras sofreram um processo de metalização durante 80 segundos.

\section{RESULTADOS E DISCUSSÕES}

\subsection{Caracterização dos rejeitos}

A análise difratométrica (DRX) realizadas na amostra de rejeito de caulim apresentou como principais componentes mineralógicos em ordem decrescente de intensidade, a Caulinita (C) e o Quartzo (Q). Observe a figura 2.

Figura 2 - Resultados do DRX do caulim (esquerda) e da lama vermelha (direita)
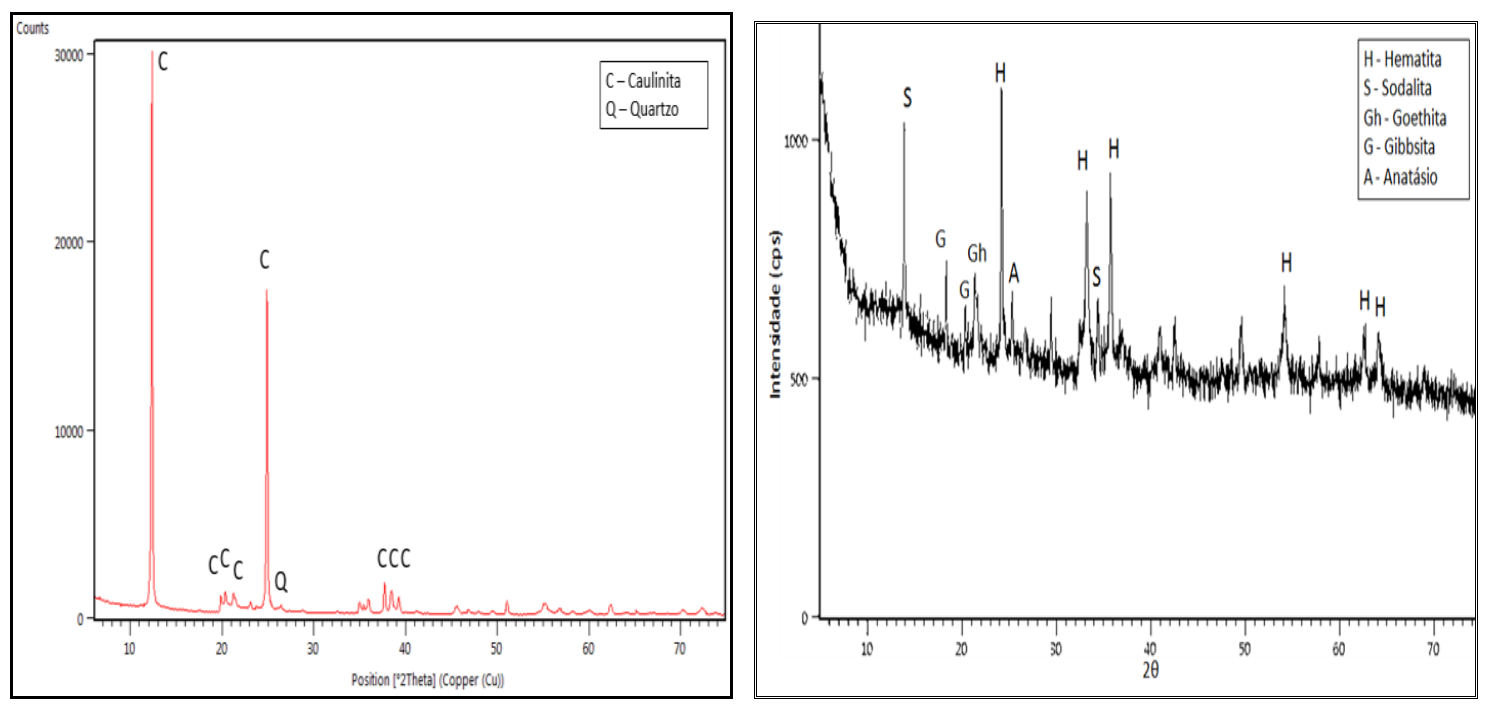

$\mathrm{Na}$ análise do caulim, a caulinita encontra-se em maior quantidade, conforme o esperado, conforme Brito (2018) com resíduo "in natura". As amostras de rejeito industrial de lama vermelha apresentaram como principais componentes mineralógicos em ordem decrescente de intensidade a Hematita $(\mathrm{H})$, Soldalite (S), Gibsita (G), Goethita (Gh) e Anatásio (A) (Costa, 2016).

\subsection{Propriedades mecânicas}

Os compósitos poliméricos com inserção de rejeitos industriais foram avaliados quanto a sua resistência mecânica por meio de ensaio de tração, alongamento e módulo de elasticidade, tais resultados são apresentados nas Tabelas 01 e 02. 


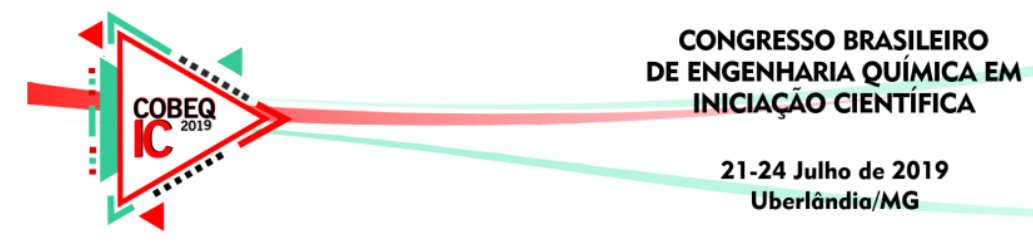

Tabela 1 - Resultados de resistência à tração dos compósitos com inserção de rejeitos industrial de Caulim

\begin{tabular}{|c|c|c|c|c|c|}
\hline $\begin{array}{c}\text { Tipos de } \\
\text { amostra }\end{array}$ & $\begin{array}{c}\text { Proporção } \\
\text { de carga } \\
(\%)\end{array}$ & $\begin{array}{c}\text { Fração } \\
\text { mássica (FM) } \\
(\mathrm{g})\end{array}$ & $\begin{array}{c}\text { Resistência } \\
\text { tração (MPA) } \\
(\text { Desvio } \\
\text { padrão) }\end{array}$ & $\begin{array}{c}\text { Alongamento } \\
(\mathrm{mm})\end{array}$ & $\begin{array}{c}\text { Módulo de } \\
\text { elasticidade } \\
(\mathrm{GPA})\end{array}$ \\
\hline \hline \multirow{2}{*}{$\begin{array}{c}\text { Matriz } \\
\text { Pura }\end{array}$} & 0 & 317,40 & $19,54( \pm 3,05)$ & 4,84 & 0,81 \\
\hline \multirow{2}{*}{$\begin{array}{c}\text { Rejeito } \\
\text { industrial } \\
\text { de caulim }\end{array}$} & $\mathrm{RCa} 10$ & 31,74 & $27,53( \pm 6,28)$ & 4,77 & 1,06 \\
\cline { 2 - 6 } & $\mathrm{RCa} 20$ & 63,48 & $30,78( \pm 6,56)$ & 4,70 & 1,24 \\
\cline { 2 - 6 } & $\mathrm{RCa} 30$ & 95,22 & $31,44( \pm 4,39)$ & 5,20 & 1,13 \\
\cline { 2 - 6 } & $\mathrm{RCa} 40$ & 126,96 & $27,77( \pm 2,49)$ & 5,87 & 1,19 \\
\hline
\end{tabular}

O ensaio realizado com compósitos de matriz polimérica com inserção de rejeitos industriais de caulim que apresentou o comportamento superior, foi a carga de $30 \%$ com tração de 31,44 MPa

Tabela 2 - Resultados de resistência à tração dos compósitos com inserção de rejeito industrial de lama vermelha.

\begin{tabular}{|c|c|c|c|c|c|}
\hline $\begin{array}{c}\text { Tipos de } \\
\text { amostra }\end{array}$ & $\begin{array}{c}\text { Proporção } \\
\text { de carga } \\
(\%)\end{array}$ & $\begin{array}{c}\text { Fração } \\
\text { mássica (FM) } \\
(\mathrm{g})\end{array}$ & $\begin{array}{c}\text { Resistência } \\
\text { tração (MPA) } \\
\text { (Desvio } \\
\text { padrão) }\end{array}$ & $\begin{array}{c}\text { Alongamento } \\
(\mathrm{mm})\end{array}$ & $\begin{array}{c}\text { Módulo de } \\
\text { elasticidade } \\
\text { (GPA) }\end{array}$ \\
\hline \hline $\begin{array}{c}\text { Matriz } \\
\text { Pura }\end{array}$ & 0 & 317,40 & $19,54( \pm 3,05)$ & 4,84 & 0,81 \\
\hline $\begin{array}{c}\text { Rejeito } \\
\text { industrial } \\
\text { de lama } \\
\text { vermelha }\end{array}$ & RLV 10 & 31,74 & $27,89( \pm 7,18)$ & 4,77 & 1,06 \\
\cline { 2 - 6 } & RLV 20 & 63,48 & $32,32( \pm 4,99)$ & 4,70 & 1,24 \\
\cline { 2 - 6 } & RLV 30 & 95,22 & $25,80( \pm 5,35)$ & 5,20 & 1,13 \\
\hline
\end{tabular}

A fração que apresentou resultado superior nos ensaios realizados com rejeito industrial de lama vermelha foi referente a de $20 \%$ com resistência a tração de $32,32 \mathrm{MPa}$.

Em uma análise geral, ambos resíduos industriais apresentaram aumento da resistência comparada a matriz plena. Os melhores desempenhos em resistência corresponderam em porcentagens de cargas distintas. Para o rejeito de caulim o melhor resultado foi de $30 \%$, já para lama vermelha de $20 \%$.

Em estudos desenvolvidos com caulim, como (Lima 2007) verifica-se a influência da interação da superfície ativa diferente deste mineral com o polímero, resultando na variação do comportamento físico-químico do compósito, ou seja, a adesão da carga na matriz polimérica os resultados irão diferenciar de porcentagem de resíduo para outro.

Segundo pesquisas de (Zhang et al 2011) com lama vermelha utilizando cargas de até $50 \%$, foi verificado que as amostras a partir de $20 \%$ decresceram devido aglomeração das 


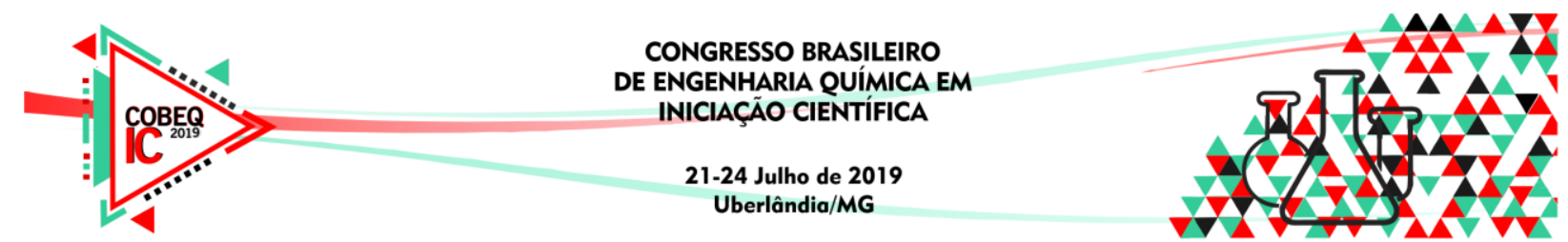

partículas. Logo, pode-se explicar a maior resistência mostrada na Tabela 2 e o declínio da resistência com maiores proporções. Além de observado através da microscopia o agrupamento das porções de lama vermelha.

Verificou-se o aumento do alongamento nas cargas de caulim de $30 \%$ e $40 \%$ comparado a matriz pura e com rejeito de lama vermelha. Quanto ao módulo de elasticidade ambos os resultados foram satisfatórios, porém o valor máximo correspondeu a porcentagem de lama vermelha de $20 \%$ com 1,33 GPA.

\subsection{Microscopia eletrônica de varredura (MEV)}

A figura 3 abaixo representa os resultados do MEV de ambas placas salientando as características mais importantes do corpo de prova.

Figura 3 - MEV do compósito com carga mineral de 40\% de caulim (esquerda) e lama vermelha de $20 \%$ (direita), ampliada 40 vezes
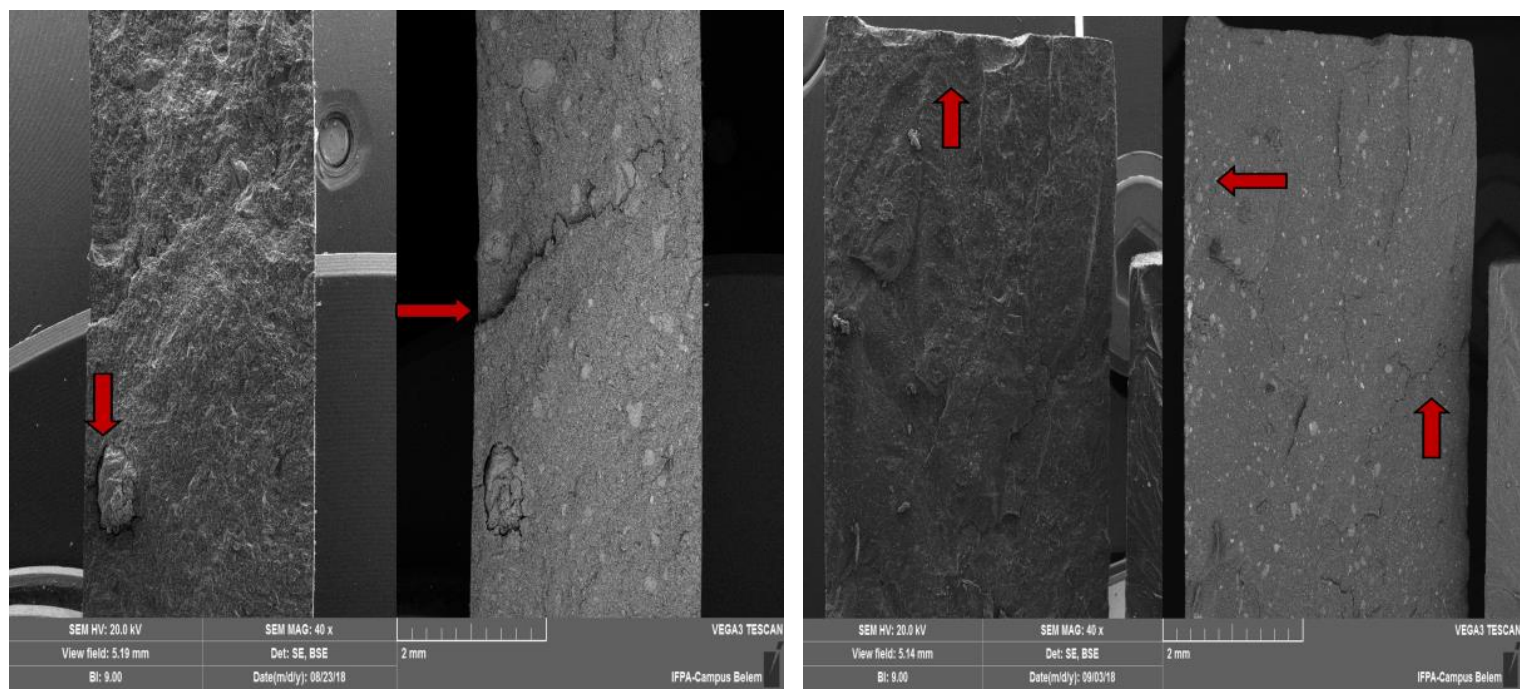

Observa-se na superfície algumas fraturas e imperfeições após a realização dos ensaios de resistência a tração. Além de apresentar formação de particulados de caulim, contudo as partículas são dispersas (esquerda). Enquanto na figura da direita, a matriz polimérica da lama vermelha apresenta tamanho uniforme de partículas, com pequenas aglomerações na borda da amostra, com poucas deformações e com pequena fratura.

\section{CONCLUSÃO}

Após a análise os resultados dos compósitos apresentaram boa ancoragem dos rejeitos de matriz polimérica dependendo da carga mineral inserida. A análise de difração de raio-X mostrou minerais esperados nas amostras estudadas. Enquanto ao ensaio de tração, o resíduo incorporado a resina atingiu valor de $32,32 \mathrm{MPa}$, correspondente a $20 \%$ de lama vermelha. A amostra de caulim pode-se atingir valores de resistência próxima caso aumente a carga, todavia, vale ressaltar que quanto maior carga mais difícil será a homogeneização, impregnação e relação matriz/mineral. Nas análises morfológicas das placas de compósitos 


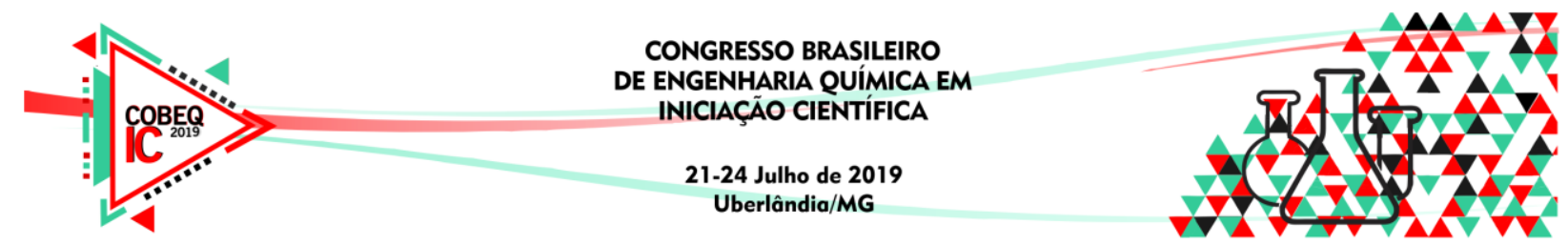

revelaram a distribuição das partículas ao longo do corpo de prova e regiões de fraturas em ambas, apenas se diferenciando em tamanho.

\section{REFERÊNCIAS}

Albano, C.; Gonzalez, J.; Ichazo, M.; Rosales, C.; Urbina de Navarro, C.; Parra, C. Mechanical and morphological behavior of polyolefin blends in the presence of $\mathrm{CaCO} 3$. In: Composite Structures 48. Pp. 49-58, 2000.

ASTM D30398, "Standard Test Method for Tensile Properties of Plastic (Metric)", Annual Book of ASTM Standards, Amer. Society for Testing and Materials, 2005.

BRITO, C. E.C et al. Avaliação da metacaulinita obtida de rejeito de caulim amazônico visando sua aplicação na síntese de argilominerais micáceos. Congresso Brasileiro de Engenharia de Materiais e Ciências dos Materiais. UFPA. 2018

CALLISTER, W. D. Jr. Ciência e Engenharia de Materiais: uma introdução. (Trad.) Sérgio Murilo Stamile Soares. Rio de Janeiro: LTC, 2008.Clark, J.A., 1986, Private Communication, University of Michigan, Ann Harbor.

COSTA, D. S. Estudo da influência de resíduos gerados pela indústria de mineração nas propriedades de compósitos de matriz poliéster reforçados com fibras naturais. Programa de Pós-graduação em engenharia de recursos naturais da amozôniaPRODERNA. Universidade Federal do Pará. 2016.

LIMA, A. B. T. Aplicações de Cargas Minerais em Polimeros. 2007. 87f. Dissertação (Mestrado) Escola Politécnica da Universidade de São Paulo. Universidade de São Paulo. São Paulo, 2007.

SAKAHARA, R. M.; Estudo da formação da fase cristalina Beta nos compósitos de polipropileno contendo anidrido maléico e carbonato de cálcio. 2012, $120 \mathrm{f}$. Dissertação (Mestrado em Ciências e Engenharia de Materiais). Escola Politécnica da Universidade de São Paulo.

ZHANG, Yihe et al. Red mud/polypropylene composite with mechanical and termal properties. Journal of Composite Materials, v. 45, n. 26, p. 2811-2816, 2011. 